\title{
Repartição da lâmina de irrigação, aplicada via pivô central, na cultura do milho
}

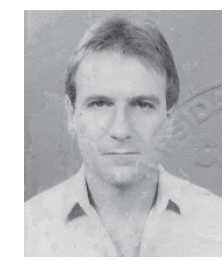

\author{
Dálcio R.B. Alves ${ }^{1}$, José A. Frizzone ${ }^{2} \&$ Durval Dourado Neto ${ }^{3}$
}

\begin{abstract}
1 ESALQ/USP. Av. Pádua Dias, 11, CEP 13418-900, Piracicaba, SP. Fone: (19) 429-4217. E-mail drbalves@terra.com.br
2 ESALQ/USP. Fone: (19) 429-4217. E-mail frizzone@carpa.ciagri.usp.br (Foto)

3 ESALQ/USP. Fone: (19) 429-4115. E-mail dourado@carpa.ciagri.usp.br
\end{abstract}

Protocolo $125-10 / 10 / 2000$

\begin{abstract}
Resumo: Este estudo foi realizado na área experimental da ESALQ-USP - Piracicaba, SP, para quantificar as frações da lâmina total de água aplicada via pivô central, correspondentes ao escoamento pelo colmo do milho (Ec), à interceptação pelo dossel da cultura (INT) e à precipitação interna (PI). Para coleta da água foram utilizados copos plásticos presos ao colmo do milho e "piscinas" montadas em lonas plásticas nos dois lados da linha de plantas, em três alturas em relação ao solo: terço inferior, médio e superior. Foram encontrados valores médios de PI, INT e Ec para as alturas de coleta, de 0,00 e 0,25 m, de 85,57 e 88,31\%, 6,56 e 5,57\%, e 7,87 e $6,12 \%$, respectivamente, para um índice de área foliar (IAF) equivalente a 3 . Nos estádios mais desenvolvidos (IAF $=4,35$ ) os maiores valores observados de PI, INT e Ec foram 83,93, 6,89 e $13,44 \%$, respectivamente, para todas as alturas de coleta analisadas. O aumento da altura de coleta de água, em relação ao nível do solo, proporciona aumento na estimativa dos valores de precipitação interna, e escoamento pelo colmo e redução nos valores de interceptação foliar.
\end{abstract}

Palavras-chave: interceptação de água, dossel, retenção da água, Zea mays L.

\section{Partitioning of depths of irrigation applied by a center pivot in a corn crop}

\begin{abstract}
This study was conducted in the experimental area of ESALQ/USP, Piracicaba, SP, to investigate and to quantify in terms of percentage of total irrigation water applied by center pivot, corresponding to flow through corn stem (Ec), interception by crop canopy (INT) and internal precipitation (PI). For the analysis, plastic recipients were fixed to the corn stem and pools (gutters on two sides of the plant row) were installed at three different heights (inferior, medium and superior part of the plant) in relation to the soil. The mean values of PI, INT and Ec for the heights of 0 and $0.25 \mathrm{~m}$ were 85.57 and $88.31 \%, 6.56$ and $5.57 \%$, and 7.87 and $6.12 \%$, respectively, for leaf area index (LAI) equivalent to 3 . For the $\mathrm{LAI}=4.35$ the largest observed values of $\mathrm{PI}$, INT and Ec were 83.93, 6.89 and $13.44 \%$, respectively, for the heights studied. The increase in height for water collection in relation to the soil level caused an increment in values of internal precipitation and stem flow, and a reduction in the values of leaf interception.
\end{abstract}

Key words: water interception, water retention, canopy, Zea mays L.

\section{INTRODUÇÃO}

O escoamento superficial, a recarga do subsolo em água e a evapotranspiração, são grandezas associadas ao ciclo hidrológico e que dependem fundamentalmente do tipo de cobertura vegetal, levando-se em consideração que a água interceptada e que deixa de atingir o solo, retorna à atmosfera, por evaporação direta. A interceptação da água de chuva através da cobertura vegetal tem sido estudada por diversos autores, sobretudo em ecossistemas florestais e culturas perenes de grande porte mas, para culturas anuais, existem poucos trabalhos publicados.

Haynes (1940) observou, por um período de três anos, a interceptação de água da chuva por diversas culturas; especificamente para o milho, verificou que de uma precipitação total de água de $682 \mathrm{~mm}$, ocorreu penetração de 479,8 $\mathrm{mm}$ através do dossel da cultura, ficando $202,7 \mathrm{~mm}$ retidos. Concluiu, ainda, que desses $202,7 \mathrm{~mm}(29,7 \%)$ de água, $155,5 \mathrm{~mm}$ escoaram pelo colmo e os $47,2 \mathrm{~mm}$ restantes $(6,9 \%)$ foram interceptados pela cultura.

Leopoldo et al. (1981) analisando a interceptação da água de chuva sob uma cobertura canavieira, verificaram que, do total de $684 \mathrm{~mm}$ de chuva precipitados sobre a cultura, $384 \mathrm{~mm}$ corresponderam à precipitação interna, $267 \mathrm{~mm}$ ao escoamento pelo colmo e $28 \mathrm{~mm}$ corresponderam à fração perdida por interceptação, representando $56,9,39,0$ e 4,1\%, respectivamente. Sob o aspecto da irrigação, esses valores são de grande importância, pois revelam que a variabilidade da 
precipitação interna ao dossel é muito variável e depende do desenvolvimento da cultura, podendo influir na eficiência de aplicação de água.

Steiner et al. (1983) estudando as perdas e a repartição de água de um pivô central sob a cultura do milho, concluíram que cerca de $50 \%$ da água que alcançou a superfície do solo, foram através do escoamento pelo colmo e o restante sob a forma de respingos, pelo dossel, da cultura. As medidas de escoamento pelo colmo e interceptação pelo dossel foram analisadas sob condições de um dossel desenvolvido, quando o índice de área foliar excedia o valor três, cujos dados mostraram que dos $33 \mathrm{~mm}$ de água aplicados, foram interceptados $2,7 \mathrm{~mm}$ pela cultura do milho, correspondendo a $8,1 \%$ da lâmina total aplicada. Os autores relatam que a capacidade de retenção de água pela cultura pode ser relativamente constante para uma condição de dossel cheio, mas que a percentagem de água armazenada pelo dossel depende da lâmina aplicada em cada irrigação, além das características da variedade, espaçamento de plantas e índice de área foliar. Chaves et al. (1996) verificaram que 22,3\% da quantidade de água precipitada foram interceptados pela cultura do feijoeiro.

Conte \& Leopoldo (1986) estimando a retenção de água de chuva pelo dossel do milho, durante todo o ciclo da cultura, verificaram interceptação foliar de $52,3 \mathrm{~mm}$, de um total precipitado de $646,1 \mathrm{~mm}$, correspondendo a $8,1 \%$ do total precipitado. O escoamento através do colmo foi $143,7 \mathrm{~mm}$, correspondendo a $22 \%$. De acordo com as observações realizadas, os autores comentam que o desenvolvimento máximo, em termos de massa foliar, ocorre entre os $95^{\circ}$ e $105^{\circ}$ dias da cultura.

Valores de retenção foliar de 1,2 e 2,6 mm de lâmina de água em diferentes fases do ciclo do milho, com diferentes emissores em pivô central, foram encontrados por Pessoa (1994). Folegatti et al. (1998) avaliando a intercepção foliar de lâminas de irrigação por aspersão convencional na cultura do milho, encontraram que 44,5 e $50 \%$ da precipitação efetiva alcançaram a superfície do solo, via escoamento pelo colmo, nas parcelas que receberam água a $3 \mathrm{e} 4 \mathrm{~mm} \mathrm{~h}^{-1}$, enquanto na parcela com intensidade de $9 \mathrm{~mm} \mathrm{~h}^{-1}$, o escoamento para o colmo reduziu para $38,8 \%$. Os autores comentam que o aumento simultâneo do escoamento pelo colmo e da precipitação interna ocorre pela diminuição das perdas por intercepção. Das pesquisas realizadas, verifica-se que a interceptação de água pela cultura de milho é muito variável, devendo ser determinada para cada situação específica, no que se refere ao índice de área foliar, espaçamento, cultivar, distribuição de folhas (arquitetura da planta) entre outros.

Este trabalho teve como objetivo quantificar a distribuição horizontal da lâmina de água aplicada via pivô central, na cultura do milho, e sua retenção no dossel das plantas, em diferentes estádios de desenvolvimento.

\section{MATERIAL E MÉTODOS}

Um experimento com milho fertirrigado foi implantado no dia 28 de agosto de 1998, na área experimental de irrigação do Departamento de Engenharia Rural, na Escola Superior de Agricultura "Luiz de Queiroz" ESALQ-USP, em Piracicaba, SP. As coordenadas geográficas são: $22^{\circ} 42^{\prime}$ de latitude sul, $47^{\circ} 38^{\prime}$ de longitude oeste e altitude de $540 \mathrm{~m}$. De acordo com o sistema de classificação de Köppen, o clima do local é do tipo CWA, subtropical úmido (Bezerra, 1995).

O sistema de irrigação utilizado foi o pivô central, com as seguintes características: comprimento total do equipamento, $89,27 \mathrm{~m}$ ( 1 torre), alcance efetivo do canhão final $15 \mathrm{~m}$, raio efetivo irrigado $104,27 \mathrm{~m}$, área irrigada 3,42 ha, lâmina bruta de irrigação de $15 \mathrm{~mm} \mathrm{em} 24 \mathrm{~h}$, altura dos difusores $4,6 \mathrm{~m}$, velocidade máxima da última torre $180 \mathrm{~m} \mathrm{~h}^{-1}$, tempo mínimo para 1 volta $2,14 \mathrm{~h}$ e vazão de $21,35 \mathrm{~m}^{3} \mathrm{~h}^{-1}$.

O híbrido de milho utilizado foi o CARGIL 909, semeado em espaçamento de $0,85 \mathrm{~m}$ entre linhas e 5 plantas por metro linear, com população aproximada de 64.000 plantas ha $^{-1}$. A área experimental foi de 2,3 ha, correspondendo a, aproximadamente, $3 / 4$ da área total do pivô. Para a adubação de plantio foram utilizados $50 \mathrm{~kg} \mathrm{ha}^{-1}$ de $\mathrm{K}_{2} \mathrm{O}, 80 \mathrm{~kg} \mathrm{ha}^{-1}$ de $\mathrm{P}_{2} \mathrm{O}_{5}$ e $30 \mathrm{~kg} \mathrm{ha}^{-1} \mathrm{de} \mathrm{N}$.

Com base nos trabalhos de Leopoldo et al (1981), Steiner et al. (1983), Conde \& Leopoldo (1986), Silva et al. (1994) e em testes preliminares realizados na mesma área, definiu-se a metodologia mais apropriada para este trabalho. Os testes foram iniciados quando as plantas apresentaram 8 folhas. Selecionaram-se três parcelas paralelas de $80 \mathrm{~m}^{2}$, localizadas perpendicularmente em relação à lateral do pivô central, de forma que todas recebiam água dos mesmos difusores. No estádio de desenvolvimento correspondente a 8 folhas, reservatórios de água em lona plástica, doravante denominados "piscinas", e coletores plásticos com volume de $500 \mathrm{~mL}$ e área da seção de coleta de $5,03 \times 10^{-3} \mathrm{~m}^{2}$, foram colocados nas alturas de $0,00 \mathrm{e}$ $0,25 \mathrm{~m}$ em relação ao nível do solo. Para se coletar a precipitação interna que passava através do dossel da cultura, duas "piscinas", com formato retangular de $0,80 \times 0,95 \mathrm{~m}$, foram montadas em cada lado da linha de plantas, suportadas por hastes metálicas e de madeira.

Para a medição do volume de água escoado pelo colmo do milho, instalaram-se coletores plásticos (volume de $500 \mathrm{~mL}$ ) envolvendo-o; para isto, fez-se um corte longitudinal na face lateral do coletor, com abertura cilíndrica no fundo, adaptando-o no colmo do milho através de um estrangulamento, para obter boa aderência; depois de feita esta fixação, procedeu-se à vedação com massa de calafetar, na parte inferior do recipiente plástico, para eliminar os possíveis vazamentos.

As "piscinas" foram instaladas na mesma altura dos coletores no colmo e a extração da água dos coletores foi verificada através de seringas sem agulha conectando-se, à sua ponta, um microtubo para auxiliar a retirada da água no ponto mais profundo do coletor. O volume de água coletado foi medido por uma proveta com graduação de $1 \mathrm{~mL}$; por sua vez, no estádio de desenvolvimento em que as plantas apresentavam mais que 12 folhas, as "piscinas" e os coletores foram instalados em três alturas $(0,00 ; 0,50$ e 1,40 m) em relação ao nível do solo.

Simultaneamente, realizaram-se testes para se avaliar a uniformidade de distribuição de água do pivô, demarcando-se uma área de 12 × $8 \mathrm{~m}$, paralela às parcelas e à lateral do pivô, sob os mesmos seis emissores que irrigavam as três parcelas. A disposição dos coletores em três linhas paralelas se deu de forma retangular, com 10 coletores por linha, espaçados de $0,50 \times 0,50 \mathrm{~m}$. Todas as avaliações foram feitas aproximadamente às $6: 30 \mathrm{~h}$, para minimizar os efeitos do vento nas irrigações. 
A perda por interceptação foliar foi calculada pela expressão:

$$
\mathrm{INT}=\mathrm{PT}-(\mathrm{PI}+\mathrm{Ec})
$$

em que:

INT - interceptação foliar, mm

PT - precipitação total, $\mathrm{mm}$

PI - precipitação interna, $\mathrm{mm}$

Ec - escoamento pelo colmo, $\mathrm{mm}$

A área foliar da cultura foi determinada selecionando-se três plantas de cada parcela, que apresentavam características semelhantes às das plantas utilizadas para quantificar os volumes de água retidos nas diferentes alturas de coleta. A área foliar foi medida utilizando-se o medidor LICOR, modelo LI 3100, em todas as observações realizadas; posteriormente, calculou-se o índice de área foliar médio nos diferentes estádios de desenvolvimento da cultura.

\section{RESULTADOS E DISCUSSÃO}

No período de 28/08/98 a 16/12/98 foram feitas nove observações para se quantificar a precipitação total, precipitação interna e escoamento pelo colmo do milho, além de aplicada uma lâmina média de $3,0 \mathrm{~mm}$ por irrigação, com o relê percentual do pivô ajustado em $40 \%$ e pressão de serviço de $350 \mathrm{kPa}$.

$\mathrm{Na}$ Figura 1 verificam-se as percentagens para precipitação interna (PI), escoamento pelo colmo (Ec) e interceptação foliar (INT) em relação à lâmina total de irrigação $(\mathrm{PT}=100 \%)$ nas alturas de coleta de 0,00 e $0,25 \mathrm{~m}$ e índices de área foliar de 3,23 e 1,09. Verificaram-se valores médios de PI de 85,57 e $88,31 \%$

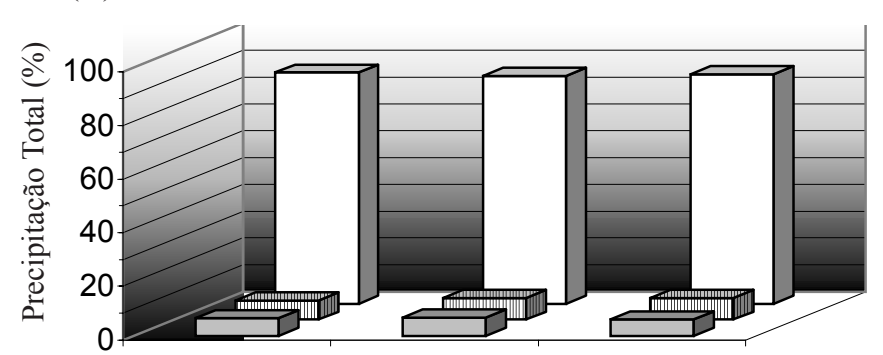

(B)

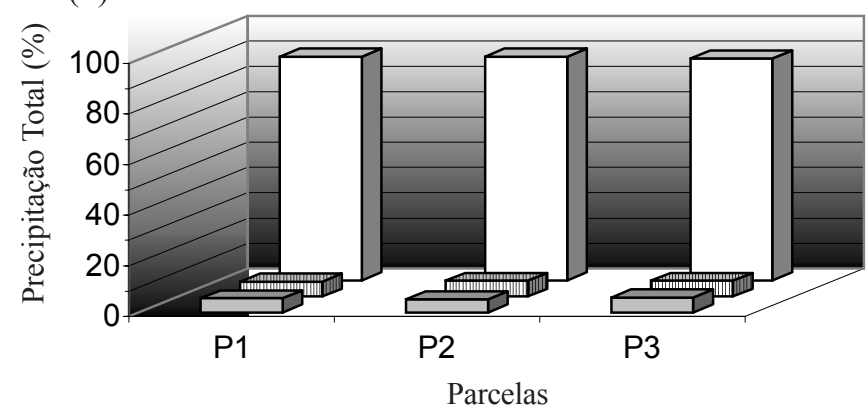

Figura 1. Valores percentuais de precipitação interna (PI), escoamento pelo colmo (Ec) e interceptação foliar (INT) em relação à precipitação total para as três parcelas analisadas: (A) $\mathrm{IAF}=3,13$ e altura de coleta de água $0,00 \mathrm{~m}$ em relação ao solo; (B) IAF $=1,09$ e altura de coleta de água $0,25 \mathrm{~m}$ em relação ao solo

nas alturas de 0,00 e $0,25 \mathrm{~m}$, respectivamente. A precipitação interna coletada nas "piscinas" na altura de $0,25 \mathrm{~m}$, foi maior, porque somente a área foliar acima deste plano contribuía para a retenção de água pelas folhas. Encontraram-se valores médios de INT de 6,56 e 5,57\% e Ec de 7,87 e 6,12\%, para as alturas de 0,00 e $0,25 \mathrm{~m}$, respectivamente, enquanto valores inferiores de precipitação interna (70 e 69,7\%) foram encontrados por Haynes (1940) e Conte \& Leopoldo (1986) respectivamente, em decorrência da metodologia utilizada e da cultivar, com diferentes arquitetura e população de plantas. Estudos realizados por Folegatti \& Paz (1998) relatam que a partição da precipitação total em precipitação interna, o escoamento pelo colmo e interceptação foliar, variam de acordo com a lâmina aplicada.

Para as análises realizadas quando as plantas apresentavam maior desenvolvimento, com IAF variando de 4,29 a 4,78, utilizou-se mais um plano horizontal de coleta $(1,40 \mathrm{~m}) \mathrm{com}$ medidas feitas nos terços médio, inferior e superior do milho $(0,00,0,50$ e $1,40 \mathrm{~m})$. Na Figura 2 mostram-se os resultados

(A)

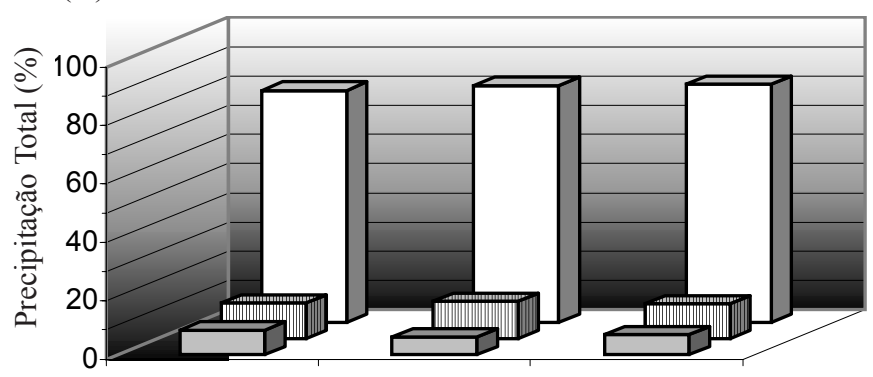

(B)

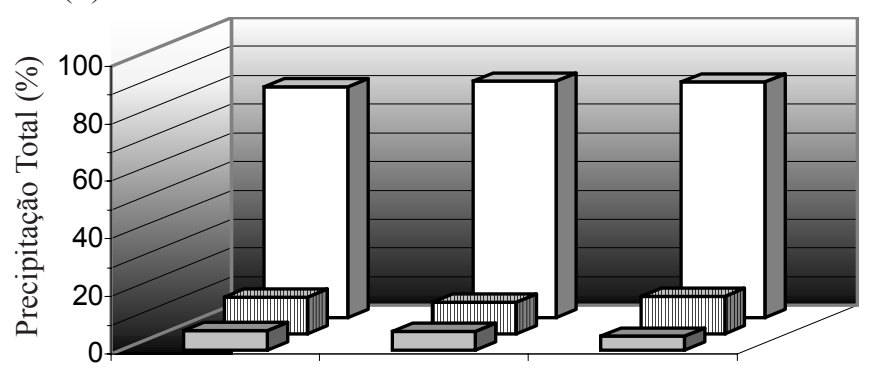

(C)

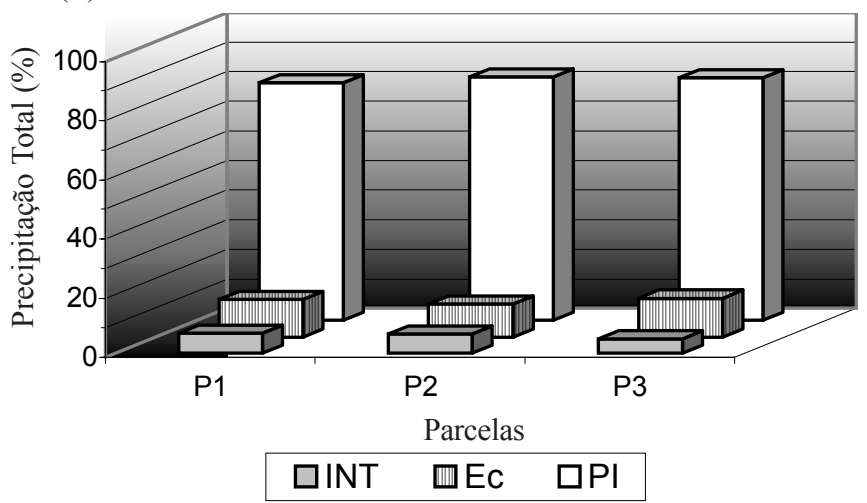

Figura 2. Valores percentuais de precipitação interna (PI), escoamento pelo colmo (Ec) e interceptação foliar (INT) em relação à precipitação total, para as três parcelas analisadas: (A) $\mathrm{IAF}=4,35$ e altura de coleta de água $0,00 \mathrm{~m}$ em relação ao solo; (B) IAF $=3,64$ e altura de coleta de água $0,50 \mathrm{~m}$ em relação ao solo e $(\mathrm{C}) \mathrm{IAF}=0,75$ e altura de coleta de água $1,40 \mathrm{~m}$ em relação ao solo 
obtidos para as percentagens das repartições de PI, Ec e INT com relação à PT, para diferentes valores de IAF e para as três alturas de coleta de água.

Para as coletas no plano inferior (altura de $0,00 \mathrm{~m}$ ) com IAF de 4,35, observaram-se valores médios de Ec iguais a 12,24\%, INT de $7,21 \%$ e PI de $80,55 \%$, em relação à lâmina total aplicada, de $3,05 \mathrm{~mm}$. Os valores percentuais de PI, observados para altura de coleta de $0,00 \mathrm{~m}$ em função do IAF, variaram de 79,34 a $81,31 \%$, com uma variação de 11,8 a $12,79 \%$ para Ec, e de 6,23 a $6,89 \%$ para INT (Figura 2). A magnitude dessas variações não foi acentuada devido, provavelmente, à pequena variação do IAF $(4,29$ a 4,78). Nos coletores instalados a $0,50 \mathrm{~m}$ de altura, os maiores valores de PI, Ec e INT foram 82,30, 13,11 e 6,89\%, respectivamente, porém os menores valores de PI, Ec e INT foram da ordem de $80,33,11,15$ e $4,92 \%$, respectivamente, para o IAF médio de 3,64 (Figura 2).

Para as coletas realizadas a 1,40 m em relação à superfície do solo, quando a cultura apresentava IAF médio de 0,75 , verificaram-se os maiores valores de PI, Ec e INT, respectivamente, de $83,93,13,44$ e $4,26 \%$, mas os menores valores de PI, Ec e INT foram 82,62, 13,11 e 2,62\%, respectivamente (Figura 2). As maiores variações obtidas para PI e Ec foram verificadas para a altura de coleta de $0,50 \mathrm{~m}$, em decorrência da maior área foliar de contribuição, da desuniformidade das folhas e da contribuição de folhas de plantas próxima à área de controle.

Comparando-se os dados de coleta de água para a altura de $0,0 \mathrm{~m}$ durante o desenvolvimento da cultura, verificou-se que, para um aumento de $39 \%$ no IAF, a PI reduziu em 5,86\%, enquanto os valores de Ec e INT aumentaram 55,53 e 9,90\%, respectivamente (Tabela 1). Dentre as variáveis de repartição da precipitação total, o escoamento pelo colmo (Ec) apresentou o maior índice de aumento, causado pelo acréscimo do diâmetro do colmo em conseqüência do desenvolvimento da cultura. Conte \& Leopoldo (1986) relatam que existe tendência do percentual de escoamento do colmo crescer com o aumento da idade das plantas. Destacam, ainda, que, com o aumento do número de folhas durante o desenvolvimento da cultura, surgem locais de deposição de água no contado caule-folha; todavia, conforme salientam Parkin \& Codling (1990) nem toda água interceptada pela cultura é necessariamente perdida, uma vez que parte dela pode retornar à superfície do solo, através do escoamento pelo colmo.

Tabela 1. Variação (\%) dos valores médios de precipitação interna (PI), escoamento pelo colmo (Ec) e interceptação foliar (INT) em dois índices de área foliar (IAF) analisados, para a altura de coleta de $0,00 \mathrm{~m}$ em relação ao nível do solo

\begin{tabular}{ccccc}
\hline $\begin{array}{c}\text { Altura de Coleta } \\
(\mathrm{m})\end{array}$ & $\begin{array}{c}\mathrm{IAF} \\
\left(\mathrm{m}^{2} \mathrm{~m}^{-2}\right)\end{array}$ & $\begin{array}{c}\mathrm{Ec} \\
(\%)\end{array}$ & $\begin{array}{c}\text { INT } \\
(\%)\end{array}$ & $\begin{array}{c}\text { PI } \\
(\%)\end{array}$ \\
\hline 0,0 & 3,13 & 7,87 & 6,56 & 85,57 \\
0,0 & 4,35 & 12,24 & 7,21 & 80,55 \\
\hline Variação $(\%)$ & 39,00 & 55,53 & 9,90 & 5,86 \\
\hline
\end{tabular}

Os resultados indicam que os valores médios de PI e Ec tendem a crescer com o aumento da altura de coleta, e os valores médios de INT diminuem com o aumento da mesma, o que é confirmado por Stone et al. (1994) atribuindo-se esta constatação à menor área foliar de contribuição acima das maiores alturas de coleta na planta, confirmando o efeito funil da folhagem do milho.

\section{CONCLUSÕES}

1. O aumento do índice de área foliar promove redução na precipitação interna e aumento no escoamento pelo colmo e na interceptação foliar.

2. O aumento da altura de coleta de água em relação ao nível do solo proporciona aumento na estimativa dos valores de precipitação interna e escoamento pelo colmo, além de redução nos valores de interceptação foliar.

\section{LITERATURA CITADA}

Bezerra, F.M.L. Coeficientes de cultura e efeitos de déficits hídricos nos diferentes estádios fenológicos sobre a produção da batata (Solanum tuberosum, L.). Piracicaba:ESALQ/USP, 1995. 131p. Tese Doutorado

Chaves, J.G.; Leopoldo, P.R.; Conte, M. de L. Modelo simplificado para balanço hídrico de culturas: Determinação da altura de chuva interceptada. In: Congresso Brasileiro de Engenharia Agrícola, 25, e Congreso Latinoamericano de Ingeníeria Agrícola, 2, Bauru, 1996. Resumos... Bauru: Sociedade Brasileira de Engenharia Agrícola, 1996. p.277. CD-Rom

Conte, M.L.; Leopoldo, P.R. Estimativa da retenção de água de chuva pela cultura do milho. Engenharia Agrícola, Botucatu, v.10, n.1, p.47-55, 1986.

Folegatti, M.V.; Paz, V.P. da S. Interceptação foliar da lâmina de irrigação na cultura do milho sob aspersão convencional. In: Congresso Brasileiro de Engenharia Agrícola, 27, Poços de Caldas, 1998. Poços de Caldas: SBEA, 1998. Anais... v.2, p.19-21.

Haynes, J.L. Ground rainfall under vegetative canopy of crops. Journal of the American Society of Agronomy, Madison. v.32, p.176-184, 1940.

Leopoldo, P.R.; Sousa, A. de P.; Tuacek Filho, S. Interceptação da água de chuva em cultura da cana-de-açúcar. Brasil Açucareiro, Botucatu. v.98, n.6, p.9-16, 1981.

Parking, T.B.; Codling, E.E. Rainfall distribution under a corn canopy: Implications for managing agrochemicals. Agronomy Journal, Madison, v.82, p.1166-1169, 1990.

Pessoa, P.C.S. Desempenho de um sistema pivô central equipado com diferentes configurações de emissores ao longo do ciclo de uma cultura de milho. Piracicaba: ESALQ/USP, 1994, 75p. Dissertação Mestrado

Silva, C.L. da; Ramos, M.M.; Ferreira, P.A. Sediyama, G.C.; Loureiro, B.T. Medição e simulação da interceptação foliar da água na cultura do milho. Pesquisa Agropecuária Brasileira, Brasília, v. 29, n.11, p.1735-1741, 1994.

Steiner, J.L.; Kanemasu, E.T.; Clark, R.N. Spray losses and partitioning of water under a center pivot sprinkler system. Transactions of the ASAE, St Joseph, v.26, n.4, p.1128-1134, 1983.

Stone, K.C.; Stansell, J.R.; Young, J.R. Insecticide distribution through an irrigated corn canopy. Transactions of the ASAE. St Joseph, v.37, n.1, p.135-138, 1994. 